\title{
Eficácia da ciclosporina $0,05 \%$ na prevenção da perda endotelial no transplante de córnea
}

\author{
Efficacy of cyclosporine $0.05 \%$ for preventing \\ endothelial loss in corneal transplant
}

Fernando Moro', Ediberto de Magalhães², Érica Galúcio², Karine Moysés' ${ }^{1}$, Victor Coronado Antunes ${ }^{1}$, Tadeu Cvintal $^{3}$

\section{Resumo}

Objetivo: Avaliar a ação da ciclosporina $0,05 \%$ tópica na prevenção da perda endotelial no transplante de córnea. Métodos: Estudo retrospectivo de 18 olhos submetidos a transplante penetrante por ceratocone realizados no serviço pelo mesmo cirurgião. Pacientes com microscopia especular com $<$ ou igual a 1200 células $/ \mathrm{mm}^{2}$, foram tratados com ciclosporina $0,05 \%$ tópica (grupo A) e pacientes com microscopia especular > a 1200 células $/ \mathrm{mm}^{2}$ constituiram o outro grupo (grupo B). O critério de inclusão foi a presença da microscopia especular no período pós-operatório de 6 meses, 1 ano e 2 anos. Os critérios de exclusão foram retransplantes precoces, olhos contralaterais de casos bilaterais, episódios prévios de rejeição ao enxerto, doenças oculares associadas como glaucoma. A análise estatística foi realizada pelos testes de Friedman com significância estatística. Foi realizada uma avaliação da variação percentual de perda endotelial em relação à microscopia especular base, comparada aos períodos de 6 meses x 1 ano x 2 anos. Resultados: No grupo A (pacientes que não utilizaram a ciclosporina $0,05 \%$ ) nos respectivos períodos de 6 meses, 1 ano e 2 anos, observou-se um decréscimo da variação percentual de perda endotelial estatisticamente significante $(\mathrm{p}=0,001)$. No grupo B (pacientes que utilizaram a ciclosporina $0,05 \%$ ) nos respectivos períodos de 6 meses, 1 ano e 2 anos, observou-se um decréscimo da variação percentual de perda endotelial estatisticamente não significante $(p=0,513)$. Conclusão: Os resultados mostram uma desaceleração da variação percentual de perda endotelial nos transplantes penetrantes de córnea dos pacientes que utilizaram ciclosporina, quando comparados aos pacientes não tratados topicamente com tal medicação, sugerindo eficácia na manutenção das células endoteliais e sobrevida do transplante de córnea.

Descritores: Endotélio da córnea; Ciclosporina/administração \& dosagem; Ceratocone; Células endoteliais; Transplante de córnea

\footnotetext{
${ }^{1}$ Assistentes do Departamento de Córnea do Instituto de Oftalmologia Tadeu Cvintal - São Paulo (SP), Brasil;

${ }^{2}$ Residentes do Instituto de Oftalmologia Tadeu Cvintal - São Paulo (SP), Brasil;

${ }^{3}$ Diretor do Instituto de Oftalmologia Tadeu Cvintal - São Paulo (SP), Brasil.
}

Recebido para publicação em: 06/07/2007 - Aceito para publicação em 23/10/2007 


\section{INTRODUÇÃO}

A s células endoteliais em olhos transplantados permanecem viáveis por anos após um procedimento bem-sucedido. Aquelas que morrem não são repostas, pois elas só se dividem em circunstâncias excepcionais ${ }^{(1)}$.

Muitos fatores influenciam diretamente na perda endotelial pós-transplante de córnea, desde problemas relacionados ao doador, ao trauma cirúrgico e a intercorrências pós-operatórias, dificultando a avaliação do comportamento endotelial no transplante de córnea.

A perda celular após uma ceratoplastia penetrante ocorre de maneira muito mais intensa e imprevisível que àquela observada em um olho normal (Figura 1). Assim, a falência endotelial tardia é a causa mais freqüente de perda do transplante após cinco anos da cirurgia e a sobrevida de um transplante de córnea por ceratocone diminui de forma significativa, aumentando as chances de reoperações em pacientes geralmente jovens $^{(1-2)}$.

No momento, o retransplante ou o transplante endotelial constituem as únicas maneiras de recuperar a transparência corneana (Figura 2). Provavelmente, serão encontradas maneiras de promover a manutenção ou reprodução endotelial, repopulando o transplante em fase de falência endotelial.

\section{MÉTOdos}

Realizamos a análise retrospectiva de 52 casos de transplante de córnea por ceratocone, realizados pelo mesmo cirurgião, no período entre 2000 e 2006 . O critério de inclusão foi a presença da microscopia especular no período pós-operatório de 6 meses, 1 ano e 2 anos. Os critérios de exclusão foram retransplantes precoces, olhos contralaterais de casos bilaterais, episódios prévios de rejeição ao enxerto, doenças oculares associadas como glaucoma. Pacientes com microscopia especular maior ou igual a 1200 células $/ \mathrm{mm}^{2}$ foram tratados com ciclosporina $0,05 \%$ tópica (grupo A) e pacientes com microscopia especular maior que 1200 células $/ \mathrm{mm}^{2}$ constituiram o outro grupo (grupo B). Dos 52 prontuários iniciais, obtivemos uma amostra de 18 olhos, sendo 12 para o grupo A e 6 para o grupo B. Foi considerado tempo zero de contagem das células endoteliais o tempo em que um dos grupos iniciou o uso da ciclosporina tópica. O seguimento especular foi de 2 anos de uso da medicação.

A análise especular foi realizada na córnea central e sempre pelo mesmo executante. O microscópio es-

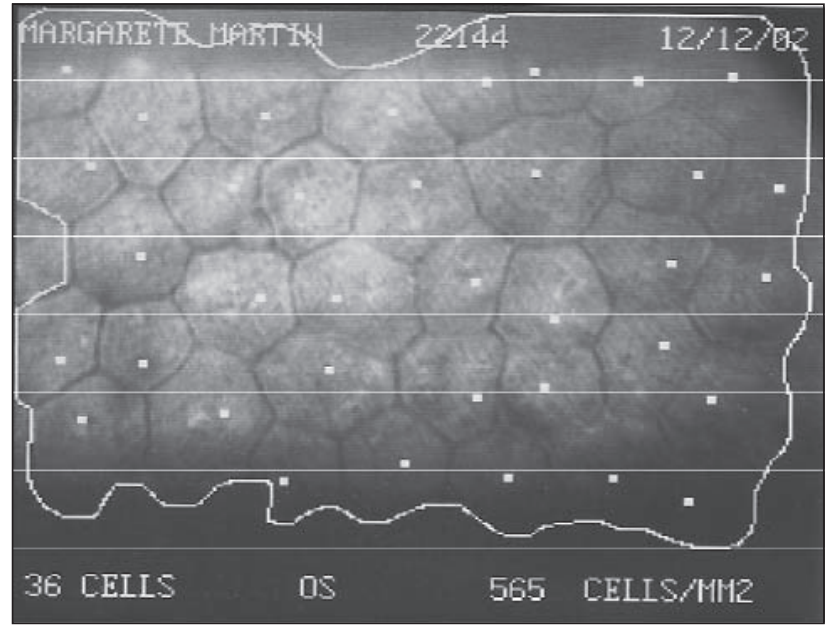

Figura 1

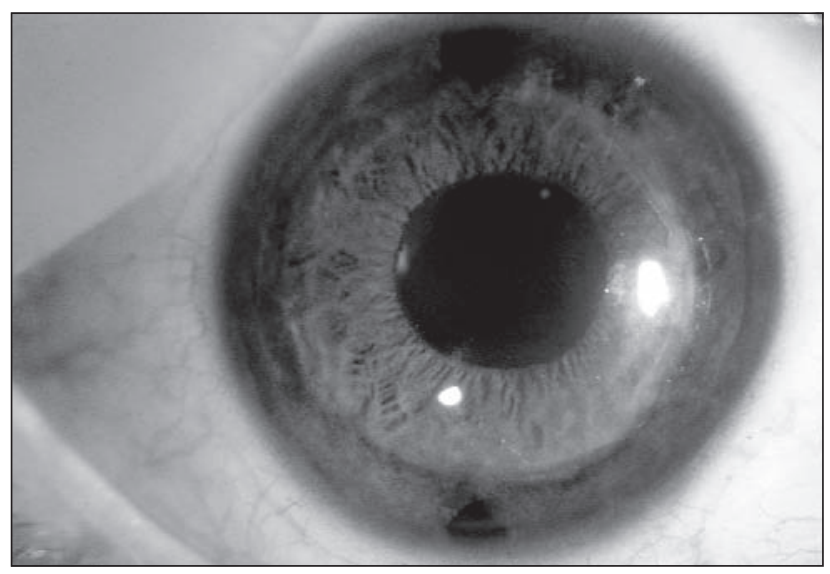

Figura 2

pecular de contato Bioptics LSM-2000 C, com sistema Bambi de análise de imagens, nos forneceu a análise morfológica em relação ao pleomorfismo e polimegatismo, além da contagem celular e paquimetria de foco endotelial. Pacientes do grupo A independentemente do tempo de pós-operatório foram submetidos ao uso tópico de ciclosporina $0,05 \%$ colírio, 1 gota, $4 \mathrm{x}$ ao dia.

Os transplantes foram realizados sob anestesia geral com a mesma técnica cirúrgica de oito pontos isolados com mononylon 10.0 e sutura contínua. Os botões doadores foram preservados em meio optisol em condições adequadas de refrigeração e utilizados até sete dias de preservação. Todas as cirurgias seguiram o mesmo protocolo pós-operatório de seguimento.

Foi aplicado o Teste de Friedman nos grupos A e $\mathrm{B}$, de acordo com seus respectivos períodos (6meses, 1 ano e 2 anos de acompanhamento com e sem a utilização da medicação). 
Tabela 1

Distribuição de sexo e idade média

\begin{tabular}{|c|c|c|c|}
\hline Grupo & Masculino & Feminino & Idade (DP) \\
\hline A & $91,67 \%(11)$ & $8,33(1)$ & $27,38(9,25)$ \\
\hline B & $83,34 \%(5)$ & $16,66(1)$ & $28 \quad(7,04)$ \\
\hline
\end{tabular}

Tabela 2

Variação percentual de perda endotelial no grupo A

Teste de Friedman - Grupo A

Ranks

\begin{tabular}{lc}
\hline & Ranks \\
\hline & Mean Rank \\
\hline 6 meses (\%) & 2,75 \\
1 ano (\%) & 2,25 \\
2 anos (\%) & 1,00 \\
\hline
\end{tabular}

Tabela 3

Teste estatístico grupo A

Test Statistics ${ }^{a}$

\begin{tabular}{lr}
\hline $\mathrm{N}$ & 12 \\
\hline Chi-Square & 19,500 \\
$\mathrm{df}$ & 2 \\
Asymp. Sig &, 000 \\
$\mathrm{p}=$ & \\
\hline
\end{tabular}

${ }^{\mathrm{a}}$ Friedman Test

Tabela 4

Teste descritivo

Descritiva

\begin{tabular}{llr}
\hline & N & Média \\
\hline 6 meses (\%) & 12 & $-2,0$ \\
1 ano (\%) & 12 & $-5,4$ \\
2 anos (\%) & 12 & $-15,8$ \\
\hline
\end{tabular}

Tabela 5

Variação percentual de perda endotelial no grupo B

Teste de Friedman - Grupo B

Ranks

\begin{tabular}{lr}
\hline & Means Rank \\
\hline 6 meses $(\%)$ & 2,00 \\
1 anos (\%) & 1,67 \\
2 anos $(\%)$ & 2,33 \\
\hline
\end{tabular}

\section{Resultados}

Ambos os grupos apresentavam uma predominância de pacientes do sexo masculino, conforme apresentado na Tabela 1, com diferença estatisticamente significante $(\mathrm{p}<0,05)$.

O tempo de pós-operatório dos grupos A e B não apresentou diferença estatística $(\mathrm{p}=0,205)$ conforme podemos observar na Tabela 2.

A densidade endotelial média nos pacientes do grupo A foi de $2379+/-358$ células $/ \mathrm{mm}^{2}$ em 6 meses, 2303+/-358,50 células $/ \mathrm{mm}^{2}$ em 1 ano e de 2055+/-388,97 células $/ \mathrm{mm}^{2}$ em 2 anos. No grupo B (pacientes que utilizaram a ciclosporina $0,05 \%$ ) foi de $932+/-327,25$ células $/ \mathrm{mm}^{2}$ em 6 meses, $889+/-242,65$ células $/ \mathrm{mm}^{2}$ em 1 ano e de $928+/-305,28$ células/ $/ \mathrm{mm}^{2}$ em 2 anos (Gráfico 1). Estes dados foram estatisticamente significantes.

Observou-se um decréscimo da variação percentual de perda endotelial estatisticamente significante $(\mathrm{p}=0,001)$ (Tabelas $2,3,4)$.

Observou-se um decréscimo da variação percentual de perda endotelial estatisticamente não significante $(\mathrm{p}=0,513)$.

As tabelas mostram uma variação percentual na perda endotelial nos transplantes penetrantes de córnea do grupo B, quando comparados ao grupo A, demonstrando alteração na perda endotelial (Tabelas 5,6,7).

\section{Tabela 6}

\section{Teste estatístico grupo B}

Test Statistics

\begin{tabular}{lr}
\hline $\mathrm{N}$ & 6 \\
Chi-Square & 1,333 \\
$\mathrm{df}$ & 2 \\
Asymp. Sig &, 513 \\
$\mathrm{p}=$ &, 513 \\
\hline
\end{tabular}

a. Friedman Test

Tabela 7

Teste descritivo

Descritiva

\begin{tabular}{llr}
\hline & N & Média \\
\hline 6 meses (\%) & 6 & $-3,2$ \\
1 ano (\%) & 6 & $-6,8$ \\
2 anos (\%) & 6 & $-3,3$ \\
\hline
\end{tabular}




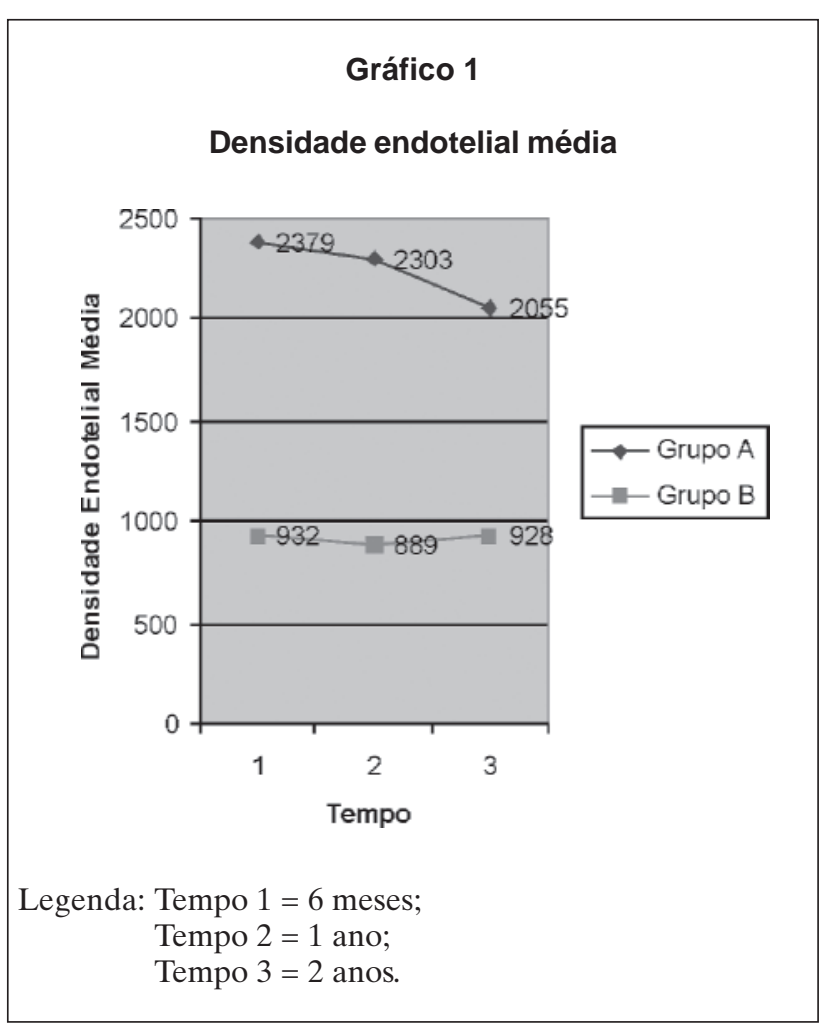

\section{DısCUSSÃO}

Com praticamente um século de existência, o transplante alográfico de córnea é o mais antigo, o mais comum e o mais bem-sucedido tipo de transplante de órgãos sólidos. Espera-se que mais de $90 \%$ dos casos ditos como de bom prognóstico, córneas avasculares, por exemplo, tenham sucesso por um período superior a dois anos. Em contraste com outros tipos de transplantes de órgãos sólidos, essa extraordinária taxa de sucesso só poderia ser reproduzida através de supressão imunológica sistêmica profunda ${ }^{(1)}$.

As células endoteliais em olhos transplantados permanecem viáveis por muitos anos, aumentando seu pleomorfismo e polimegatismo. Aquelas que morrem não são repostas, apresentando uma perda endotelial acelerada e imprevisível que por razões multifatoriais resultam na falência endotelial e conseqüente perda da transparência corneana ${ }^{(2-3)}$.

A falência endotelial tardia constitui a maior causa de perda de transplantes após 5 anos de pós-operatório, devido à perda celular endotelial contínua que se inicia na preservação do botão corneano doador, no trauma cirúrgico e no pós-operatório inicial ${ }^{(4)}$.

A perda celular após uma ceratoplastia penetrante ocorre de maneira muito mais intensa de que em um

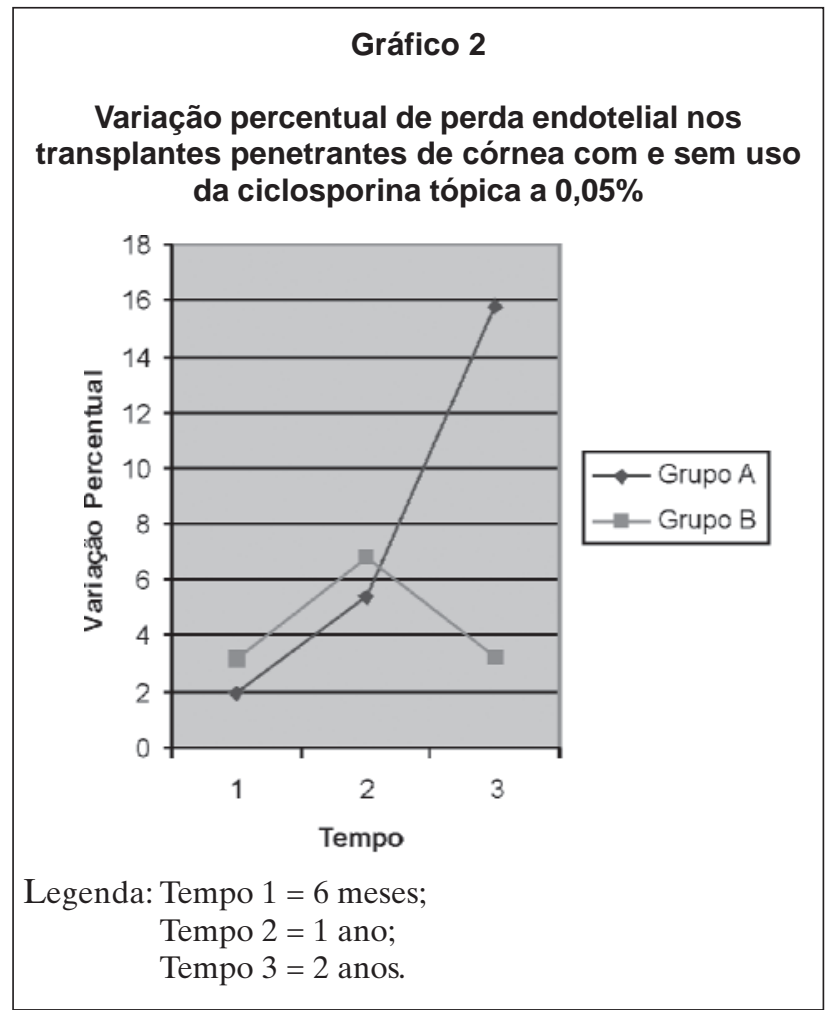

olho normal $^{(5)}$. Foi demonstrada nos primeiros anos de pós-operatório, perda de células treze vezes superior ao observado em córneas normais ${ }^{(6-7)}$.

Mesmo a partir do quinto ano de pós-operatório, as células não voltam ao normal, indicando que ainda há instabilidade endotelial ${ }^{(8)}$.

Existe uma associação consistente e estatisticamente significante entre perda endotelial pós-operatória e idade do doador, densidade endotelial do doador e idade do receptor principalmente no primeiro ano de pós-operatório ${ }^{(9)}$.

Apesar da multifatorialidade da diminuição das células endoteliais, ela está correlacionada com o tempo de pós-operatório ${ }^{(10)}$.

A perda celular varia entre 3.5 e $7 \%$ ao ano, nos dois primeiros anos, quando o botão doador perde cerca de $60 \%$ das células endoteliais. Dos três aos cinco anos, a perda é de $7.8 \%$ ao ano. Aos cinco anos, o transplante terá perdido $70 \%$ das células ${ }^{(1)}$.

O endotélio corneano central forma uma camada única e instável que apresenta perda celular contínua e acelerada, além de apresentar células morfologicamente e funcionalmente alteradas ${ }^{(11)}$.

Uma reação imunológica subclínica que não é visível ao exame da lâmpada de fenda tem sido relacionada como principal causa deste fenômeno. O enxerto é 
um tecido estranho ao organismo, no qual as células alogênicas persistem. A migração celular da córnea doadora em direção a córnea receptora corrobora esta perda em casos especiais ${ }^{(12)}$.

Apesar de não haver evidências de processos imunológicos subclínicos responsáveis pela perda endotelial acelerada no transplante de córnea, hipoteticamente, o uso da ciclosporina tópica, com suas propriedades imunossupressoras, poderia alterar o curso desta perda imunológica subclínica.

A ciclosporina, produto do fungo Tolypocladium inflatum, primeiro imunossupressor especificamente dirigido contra as células T, com ações no sistema imune, bloqueia especificamente a transcrição de genes que codificam a produção de interleucina 2, cuja indução é imprescindível para a proliferação das células $T^{(13)}$.

A sua utilização sistêmica já foi amplamente estudada e utilizada principalmente em transplantes de alto risco de rejeição. Em transplantes com leitos vascularizados, houve uma sobrevida maior em grande parte dos pacientes se mostrando eficaz na prevenção de rejeições em retransplantes e transplantes de alto risco, porém com riscos eventuais do uso crônico deste imunossupressor ${ }^{(14-16)}$.

A aplicação tópica da ciclosporina no transplante de córnea é efetiva, tendo inúmeras vantagens comparadas à sua administração sistêmica e dos corticosteróides. É capaz de atingir altas concentrações no epitélio corneano, às vezes mais alta que a obtida com a administração sistêmica da droga ${ }^{(17)}$.A penetração da droga na córnea e conjuntiva ocorre logo após sua instilação, e com a utilização da formulação $0,05 \%$ atingimos a concentração de $1550 \mathrm{ng} / \mathrm{g}$ na córnea, $713 \mathrm{ng} / \mathrm{g}$ na conjuntiva, $12 \mathrm{ng} / \mathrm{g}$ na glândula lacrimal, $1,4 \mathrm{ng} / \mathrm{g}$ no humor aquoso e menos de $0,7 \mathrm{ng} / \mathrm{g}$ na retina. Mesmo assim, os efeitos imunossupressores da ciclosporina tópica parecem não depender da penetração da câmara anterior ${ }^{(18)}$.

A aplicação tópica de ciclosporina a $0,05 \%$ não tem efetividade comparável ao acetato de prednisolona a $1 \%$ na prevenção de episódios de rejeição em transplantes de baixo risco ${ }^{(19)}$.

Já a apresentação a $2 \%$ é efetiva na redução do risco de rejeição do transplante de córnea de alto risco, como transplantes pediátricos com uma diferença estatística considerável entre o grupo com ciclosporina e controle na comparação das taxas de sobrevida do transplante $\mathrm{e}^{(20221)}$.

Com o objetivo de alterar a perda endotelial com a utilização da ciclosporina tópica $0,05 \%$, os resultados sugerem uma desaceleração da variação percentual de perda endotelial nos transplantes penetrantes de córnea do grupo de pacientes que utilizaram a ciclosporina $0,05 \%$, quando comparados ao grupo de pacientes que não utilizaram a medicação, demonstrando ser bastante benéfico na manutenção das células endoteliais e sobrevida do transplante de córnea (Gráfico 2).

As dificuldades encontradas para seleção dos pacientes foram o uso irregular da medicação, o desconforto causado pela medicação e o custo.

Durante a fase de pré-descompensação de um transplante de córnea, o paciente queixa-se de embaçamento da visão pela manhã, em dias úmidos e visão de arco íris ao redor de lâmpadas, podendo haver diminuição da acuidade visual. A microscopia especular mostra baixa população endotelial, com polimegatismo e pleomorfismo das células. A quantidade crítica de células para manter a transparência e a espessura corneana gira em torno de 500 células, sendo que às vezes encontramos córneas transparentes com 300 células e outras descompensadas com 800 células, neste caso, a função celular está afetada. A córnea se mostra muito sensível a pequenos aumentos de tensão, edemaciando rapidamente. Há grande risco de descompensação imediata se forem realizadas cirurgias intra-oculares nesta fase, tanto pelo trauma cirúrgico ao endotélio quanto pela possibilidade do aumento da pressão intra-ocular no pós-operatório, também lesiva ao endotélio ${ }^{(1)}$. Estes dados nos serviram de auxílio para estabelecer como critério de inclusão da utilização da ciclosporina tópica nos pacientes com microscopia especular maior que 1200 células $/ \mathrm{mm}^{2}$.

Enquanto o controle da proliferação endotelial não se tornar reprodutível, é imprescindível que possamos prever o comportamento endotelial no pós-operatório do transplante de córnea e procuremos alternativas para prorrogar a falência endotelial tardia.

\section{Conclusão}

Seria possível prevenir ou retardar a falência endotelial tardia, a principal causa de falência dos transplantes, através da manutenção do número das células endoteliais das córneas transplantadas. A utilização da ciclosporina tópica a $0,05 \%$ nos transplantes de córnea por ceratocone parece alterar a curva de perda endotelial do transplante de córnea. No entanto, uma observação mais prolongada com um maior número de casos se faz necessária para confirmar esta hipótese.

\section{Abstract}

Purpose: To assess the efficacy of topical cyclosporine. $05 \%$ for preventing endothelial loss in cornea transplant. Methods: Retrospective study of 18 eyes submitted to 
penetrating transplant due to keratoconus, operation carried out by the same surgeon. Patients with specular microscopy with lower than or equal to $1200 \mathrm{cells} / \mathrm{mm}^{2}$ belonged to the control group. The inclusion criterion was the occurrence of specular microscopy in the postoperative period over the 6-month, 1-year, and 2-year periods and the exclusion criterion was the occurrence of other pathologies, precocious retransplants, contralateral eyes of bilateral cases, previous rejection episodes, eye pathologies associated with glaucoma. The statistical analysis was based on Friedman's tests. After the application of Friedman's test to group A (patients who had not used the cyclosporine $.05 \%$ ) in the respective 6-month, 1-year, and 2-year periods, a statistically significant decrease in the percentage variation of endothelial loss was observed $(p=.001)$. After the application of Friedman's test to group $B$ (patients who had used the cyclosporine .05\%) in the respective 6-month, 1-year, and 2-year periods, a statistically not significant decrease in the percentage variation of endothelial loss was observed ( $p=.513)$.Results: The curves of endothelial loss went through Friedman's statistical tests in which one carried out an assessment of percentage variation of endothelial loss in relation to base specular microscopy compared to the 6-month, 1-year, and 2-year periods. Conclusion: Based on the results achieved after the application of Friedman's test, one could clearly show a deceleration in the percentage variation of endothelial loss in penetrating cornea transplants of group B (patient who had used the cyclosporine. $05 \%$ ) in comparison with group A (patients who had not used the cyclosporine .05\%), proving its beneficial effect on the maintenance of endothelial cells and survival in cornea transplant.

Keywords: Endothelium, corneal; Cyclosporine/ administration \& dosage; Keratoconus; Endothelial cells; Corneal transplantation

\section{REFERÊNCIAS}

1. Munarin MA, Moro F, Marazato F, Cvintal T. Falência endotelial tardia no transplante de córnea. In: Cvintal T. Complicações no transplante de córnea. São Paulo: Editora Santos; 2004. p. 379-93.

2. Bourne WM, Nelson LR, Hodge DO. Central corneal endothelial cell changes over a ten-year period. Invest Ophthalmol Vis Sci. 1997; 38(3):779-82.

3. Mishima S. Clinical investigations on the corneal endothelium - XXXVIII Edward Jackson Memorial Lecture. Am J Ophthalmol. 1982; 93(1):1-29.

4. Nishimura JK, Hogge DO, Bourne WM. Initial endothelial cell density and chronic endothelial cell loss rate in corneal transplants with late endothelial failure. Ophthalmology. 1999; 106(10):1962-5.
5. Abib FC, Almeida VL. Densidade endotelial durante a vida. In Abib FC, editor. Microscopia especular de córnea: manual e atlas. Rio de Janeiro: Revinter 2000. p. 25-8.

6. Bourne WM. Cellular changes in transplanted human corneas. Cornea. 2001; 20(6): 560-9.

7. Bourne WM, Hodge DO, Nelson LR. Corneal endothelium five years after transplantation. Am J Ophthalmol. 1994; 118(2): 185-96.

8. Matsuda M, Suda T, Manabe R. Serial alterations in endothelial cell shape and pattern after intraocular surgery. Am J Ophthalmol. 1984; 98(3):313-9.

9. Musch DC, Meyer RF, Sugar A. Predictive factors for endothelial cell loss after penetrating keratoplasty. Arch Ophthalmol. 1993; 111(1):80-3.

10. Obata H, Murao M, Miyata K, Sawa M. Corneal endothelial cell damage in penetrating keratoplasty. Nippon Ganka Gakkai Zasshi. 1992; 96(3):346-51. Id: Jpn.

11. Patel SV, Hodge DO, Bourne WM. Corneal endothelium and postoperative outcomes 15 years after penetrating keratoplasty. Am J Ophthalmol. 2005; 139(2):311-9.

12. Reinhard T, Böhringer D, Hüschen D, Sundmacher R. [Chronic endothelial cell loss of the graft after penetrating keratoplasty: influence of endothelial cell migration from graft to host]. Klin Monatsbl Augenheilkd. 2002; 219(6):410-6. German.

13. Castro MCR, Cvintal T. Imunossupressão sistêmica em retransplantes - esquema tríplice. In: Cvintal T. Complicações no transplante de córnea. São Paulo: Editora Santos; 2004. p. 247-50.

14. Miller K, Huber C, Niederwieser D, Gottinger W. Successful engraftment of high-risk corneal allografts with short-term immunosuppression with cyclosporine. Transplantation. 1988; 45(3):651-3.

15. Irschick E, Miller K, Berger M, Schönitzer D, Koller J, Wagner H, et al. Studies of the mechanism of tolerance induced by shortterm immunosupression with cyclosporine in high-risk corneal allograft recipients. Transplantation. 1989; 48(6):986-90.

16. Randelman JB, Stulting RD. Prevention and treatment of corneal graft rejection: current practice patterns (2004). Cornea.2006;25(3):286-90.

17. Algros MP, Angonin R, Delbosc B, Cahn JY, Kantelip B. Danger of systemic cyclosporine for corneal graft. Cornea. 2002; 21(6):613-4

18. Theng J, Zhou L, Tan D, La KW. Distribution of cyclosporin A in the cornea after topical or oral administration. J Ocul Pharmacol Ther. 2002; 18(1):83-8.

19. Mader TH, Stulting RD. High risk penetrating keratoplasty. In: Krachmer JH, Mannis MJ, Holland EJ. Cornea: surgery of the cornea and conjunctiva. St. Louis: Mosby; 1997. p. 1757-72.

20. Price MO, Price FW Jr. Efficacy of topical cyclosporine $0.05 \%$ for prevention of cornea transplant rejection episodes. Ophthalmology. 2006; 113(10):1785-90.

21. Inoue K, Amano S, Kimura C, Sato T, Fujita N, Kagawa F, et al. Long-term effects of topical cyclosporine A treatment after penetrating keratoplasty. Jpn J Ophthalmol. 2000; 44(3):302-5

ENDEREÇO PARA CORRESPONDÊNCIA

\section{Fernando Moro}

Av: Saul Navarro, 240 - Praia do Canto

CEP 29057-240 - Vitória - Espírito Santo

fmoro@uol.com.br 